\title{
Chamber Optimization for Comprehensive Improvement of Cone Crusher Productivity and Product Quality
}

\author{
Fengbiao Wu, ${ }^{1,2}$ Lifeng Ma $\mathbb{D}^{\mathrm{D}},{ }^{1}$ Guanghui Zhao, ${ }^{1}$ and Zhijian Wang ${ }^{3}$ \\ ${ }^{1}$ College of Mechanical Engineering, Taiyuan University of Science and Technology, Taiyuan 030024, China \\ ${ }^{2}$ Shanxi Institute of Energy, Taiyuan 030006, China \\ ${ }^{3}$ School of Mechanical Engineering, North University of China, Taiyuan 030051, China \\ Correspondence should be addressed to Lifeng Ma; mlf_zgtyust@163.com
}

Received 26 January 2021; Revised 17 February 2021; Accepted 5 March 2021; Published 15 March 2021

Academic Editor: Gan Feng

Copyright $\odot 2021$ Fengbiao Wu et al. This is an open access article distributed under the Creative Commons Attribution License, which permits unrestricted use, distribution, and reproduction in any medium, provided the original work is properly cited.

\begin{abstract}
This study aims to analyze the impact of key structural parameters such as the bottom angle of the mantle, the length of the parallel zone, and the eccentric angle on the productivity and product quality of the cone crusher and optimize the crushing chamber to improve the crusher performance. The amount of ore in the blockage layer was calculated by analyzing the movement state of the ore in the crushing chamber. Considering the amount of ore uplift further, the traditional mathematical model of crusher productivity was revised. Then, a mathematical model for dual-objective optimization of productivity and product quality of cone crusher was established. Furthermore, taking the existing C900 cone crusher as the research object, the influence of key parameters on the performance of the crusher was researched. And the optimal values of key structural parameters were obtained. Finally, based on the iron ore coarsely crushed by the gyratory crusher, the dynamic characteristics of the C900 cone crusher were simulated by using the discrete element method (DEM), and the simulation results are basically consistent with the numerical analysis results. Results show that considering the amount of ore uplift in the blockage layer, the revised mathematical model of crusher productivity can better characterize the actual productivity. The bottom angle of the mantle and the length of the parallel zone are within the range of $50^{\circ}-60^{\circ}$ and $140 \mathrm{~mm}-190 \mathrm{~mm}$, respectively. The productivity shows a positive correlation with the bottom angle and a negative correlation with the length of the parallel zone. But the dependence of product quality on the angle and the length is just the opposite. The eccentric angle is within the range of $1.4^{\circ}-2^{\circ}$ and its decrease has a negative effect on the productivity and product quality.
\end{abstract}

\section{Introduction}

As one of the key equipment in the bulk materials crushing system, the cone crusher is mainly used for the medium and fine crushing of bulk materials. With the continuous promotion of breaking instead of grinding, the application of cone crusher is more extensive. The crushing chamber is the key factor that determines the performance of the cone crusher. At present, Bengtsson, Gröndah, Lee et al. [1-5], Zhang et al. [6], Huang et al. [7], Khalid et al. [8], Bengtsson et al. [9], and Franks et al. [10] have studied the interparticle breakage behavior of bulk materials through the ore mechanics test system and established a productivity model, and the influence of the engagement angle, different close side settings (CSS), the mantle shaft speed, and particle shape of the cone crusher on the performance of the crusher is studied. However, the productivity model does not consider the effect of ore uplift in the blockage layer, and the bottom angle of the mantle, the length of the parallel zone, and the eccentric angle have a great influence on the chamber structure, and the chamber structure is related to the number of broken ores. Therefore, it is necessary to further study the influence of these parameters on the crushing performance. In addition, the DEM has been proved to be a very good virtual simulation environment by Cleary, Delaney et al. [11, 12], Quist et al. [13], and Chen et al. [14]. The virtual simulation environment can be used to gain a fundamental understanding regarding internal processes and operational responses. A virtual crushing platform 
can not only be used for understanding but also for the development of new crushers and for optimization purposes.

Therefore, the working process of the cone crusher is taken as the specific analysis object, and considering the amount of ore uplift, the traditional mathematical model of crusher productivity was revised. Then, a mathematical model for dual-objective optimization of productivity and product particle size distribution of cone crusher was established. Furthermore, the influence of the bottom angle of the mantle, the length of the parallel zone, and the eccentric angle on cone crusher performances is analyzed by the optimal numerical calculation method. Finally, the reliability of the optimization model and optimization algorithm of cone crusher is verified by the DEM based on the characteristics of coarse crushing ores.

\section{Cone Crusher Structure and Functional Principle}

The crushing chamber is composed of the mantle and concave, as shown in Figures 1(a) and 1(b). The drive turns the horizontal countershaft. The pinion gear on the countershaft rotates the eccentric gear. The eccentric bushing rotation causes the mantle to wobble. The functional principle of a cone crusher is to compress particles between two surfaces. The compressive action is realised by inflicting a nutational motion on the mantle while the concave remains fixed. The ore is squeezed and crushed several times along the crushing chamber from the feeding port to the discharging port, especially in the parallel section, which does the final crushing. Larger ore needs longer time between squeezes.

The crushing of ore is directly related to the compression ratio, and the bottom angle and eccentric angle determine the compression stroke of the mantle. The length of the parallel zone determines the number of ore fractures. Therefore, the productivity and particle quality of the cone crusher are affected by these structural parameters of the crushing chamber.

\section{Modified Model of Productivity considering Blockage Layer}

Productivity refers to the amount of ore processed by the crusher per unit time under the conditions of certain feed size and discharge size, which is a key indicator reflecting the performance of the crusher. The calculation results of the existing cone crusher productivity are compared with the actual production results. The calculation results are always greater than the actual production results. After analysis, because the crusher has a blockage layer in actual work, the mantle far away from the concave will fall. The ore on the side of the mantle close to the concave will arch up and cannot be discharged from the discharge port. Therefore, it is necessary to theoretically derive the amount of ore in the blockage layer and revise the existing theoretical calculation model of cone crusher productivity.
The existing theoretical calculation model of productivity is calculated based on the volume of the ore discharged from the crushing chamber once the mantle swings [15], as shown in Figure 2. The following equation represents the mathematical model:

$$
V=\Delta b \Delta l D_{c} \pi,
$$

where $V$ is the volume of the ore discharged from the crushing chamber once the mantle swings, $\Delta b$ is the thickness of the ore layer when the ore is compressed, $\Delta l$ is the ore displacement when the mantle swings, and $D_{c}$ is the average diameter of the ore compression layer, considered to be approximately equal to the bottom diameter of the mantle [16].

Considering the ore hardness and feed size, the following equation represents the productivity per minute:

$$
Q_{L}=188 \mu n \Delta l \Delta b D_{c} \rho K_{Q} K_{t},
$$

where $Q_{L}$ is productivity, $\rho$ is ore bulk density, $n$ is the mantle swing times per minute, $\mu$ is loose factor, $\mu=0.55 \sim 0.7, K_{Q}$ is ore hardness coefficient (hard ore: $K_{Q}=0.75$; medium hard or soft ore: $K_{Q}=1$ ), $K_{\mathrm{t}}$ is feed size factor, and $B$ is feed opening width, as shown in Table 1.

As shown in Figure 3, the crushing chamber formed by the mantle and the concave is divided into four areas, and the mantle rotates counterclockwise. When the mantle closes to the concave and extrudes the ore, the ore in the $A$ and $D$ areas will arch upward. That is, when the mantle is close to the concave, the ore cannot be discharged naturally and upward movement occurs.

At this time, the ore speed is consistent with the moving speed of the mantle, and the ore throughput is obtained by double-integrating the ore velocity and area in the $A$ and $D$ areas. In Figure 3, xoy plane is the cross section of the blockage layer, ois the center of the concave section, and $o^{\prime}$ is the center of the mantle section.

Therefore, the ore quantity in this area is calculated, and then the traditional productivity theory is used to subtract the ore quantity in this part, so a more accurate calculation method of productivity can be obtained. Ore velocity in the upper arch area is shown as follows:

$$
V_{\text {up }}=-\frac{S \pi}{T} \sin (2 \pi t)
$$

where $t$ is $1 / 2$ cycle, $T=(60 / n)$ (the rotating speed of the mantle is $n$ ) and $S$ is the moving distance of the mantle. Take a microelement for the upper arch area of the blockage layer, and the integral function of the upper arch zone can be expressed as follows:

$$
Q_{\mathrm{up}}=\int_{0}^{\alpha} \int_{R(\alpha)}^{R_{D}} \rho V_{\mathrm{up}}(\alpha) r \mathrm{~d} r \mathrm{~d} \alpha,
$$

where $\alpha$ is the angle enclosed by the upper arch boundary and the coordinate axis, $R(\alpha)$ is the distance from the center of the concave to the boundary of the mantle, $R_{D}$ is the radius of the concave, and $V_{\text {up }}$ is the speed of the ore in the upper arch area. 


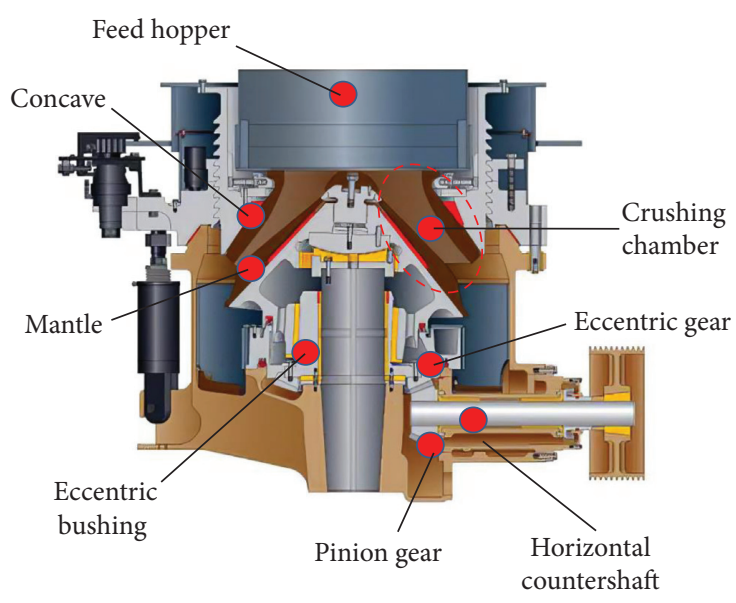

(a)

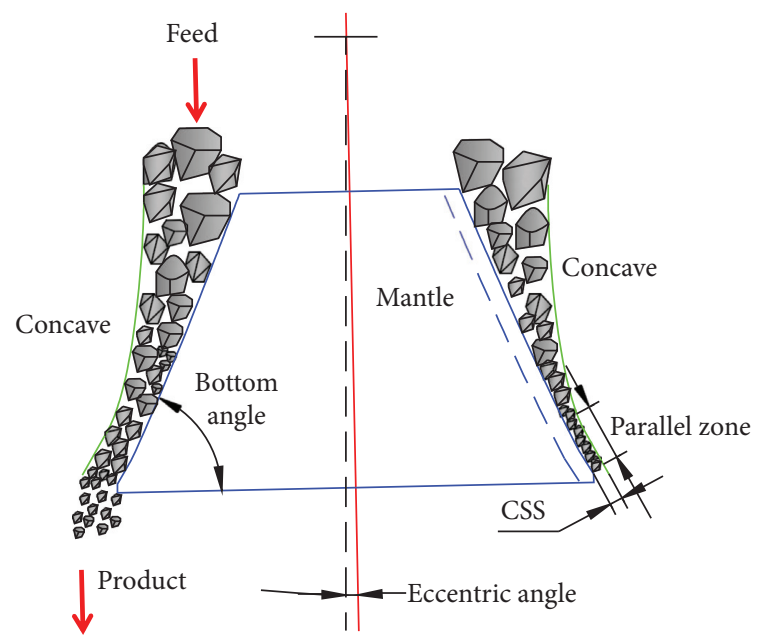

(b)

FIgURE 1: (a) Structure diagram and (b) functional principle diagram of cone crusher.

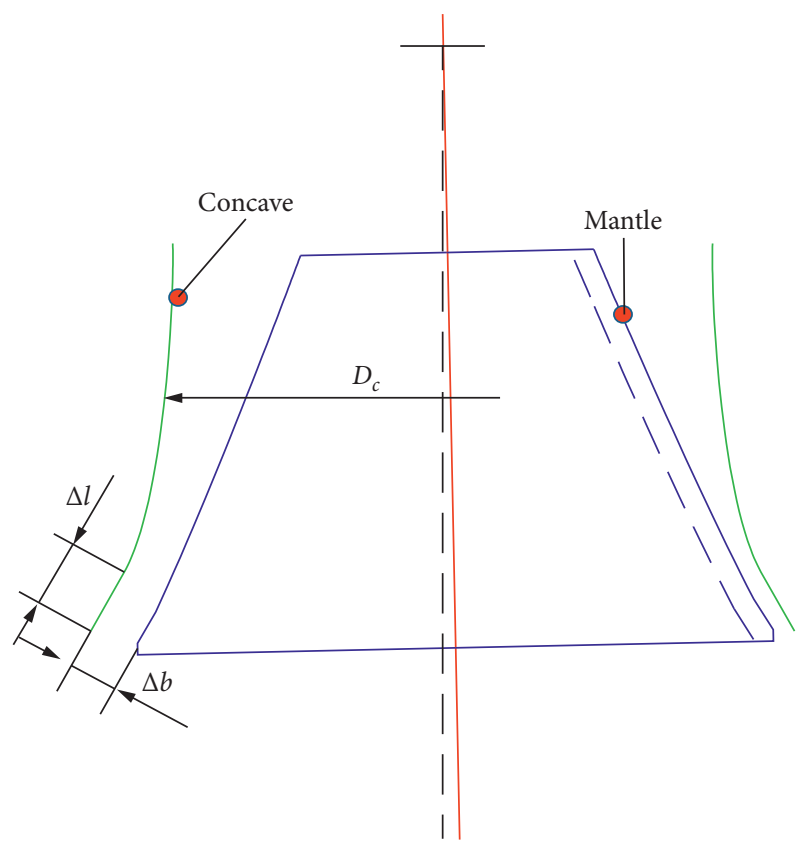

Figure 2: Traditional productivity calculation model.

In summary, equation (5) of the productivity model is shown in equations (2) and (4):

$$
Q=Q_{L}-Q_{\text {up }}=188 \mu n \Delta l \Delta b D_{c} \gamma K_{Q} K_{t}-2 \int_{0}^{\alpha} \int_{R(\alpha)}^{R_{D}} \rho V_{\text {up }}(\alpha) r \mathrm{~d} r \mathrm{~d} \alpha
$$

\section{Dual-Objective Optimization of Productivity and Product Quality}

The good performance of the cone crusher is mainly reflected in the high productivity and neat particle size distribution of crushed products. There is a strong coupling relationship between productivity optimization and product quality optimization models. Based on the principle of interparticle breakage, the kinematic characteristics of bulk materials, and the population balance modeling (PBM), a dual-objective programming model of the cone crusher is established.

In the case of ensuring the particle size of the crushed product, the productivity of the crusher should be improved as much as possible. Taking productivity as the first objective function of optimizing crusher chamber, the objective function as shown in the following equation is obtained according to equation (5):

$$
F_{1}(x)=-Q=-\left(Q_{L}-Q_{\mathrm{up}}\right) \longrightarrow \min .
$$

The mass proportion $P_{\text {css }}$ of the bulk materials whose diameter is smaller than the CSS is the main technical index to measure the particle size distribution of the crushed product. Therefore, the following equation is used as the second objective function for optimizing the chamber shape of the crusher:

$$
F_{2}(x)=-P_{\mathrm{CSS}}=-\sum_{x \leq \mathrm{CSS}}\left\{\prod_{i=1}^{K_{0}}\left[B_{i} S_{i}+\left(I-S_{i}\right)\right] F_{i}\right\} \longrightarrow \min .
$$

Equation (7) is based on the model proposed and perfected by Broadbent et al. [18] and Lynch [19] in the study of "coal crushing process." After the continuous improvement of most scholars, equation (8) of the product particle size distribution model of the material is gradually summarized:

$$
P_{\mathrm{CSS}}=\sum_{x \leq \mathrm{CSS}}\left\{\prod_{i=1}^{K_{0}}\left[B_{i} S_{i}+\left(I-S_{i}\right)\right] F_{i}\right\},
$$

where $S_{i}$ is selection function, $B_{i}$ is crushing function, $i$ is the number of crushing times the material has been subjected to, $1 \leq i \leq K_{0}, I$ is the unit matrix of feeding granularity.

For the selection function and crushing function mentioned in the above equation, Professor Evertsson of 


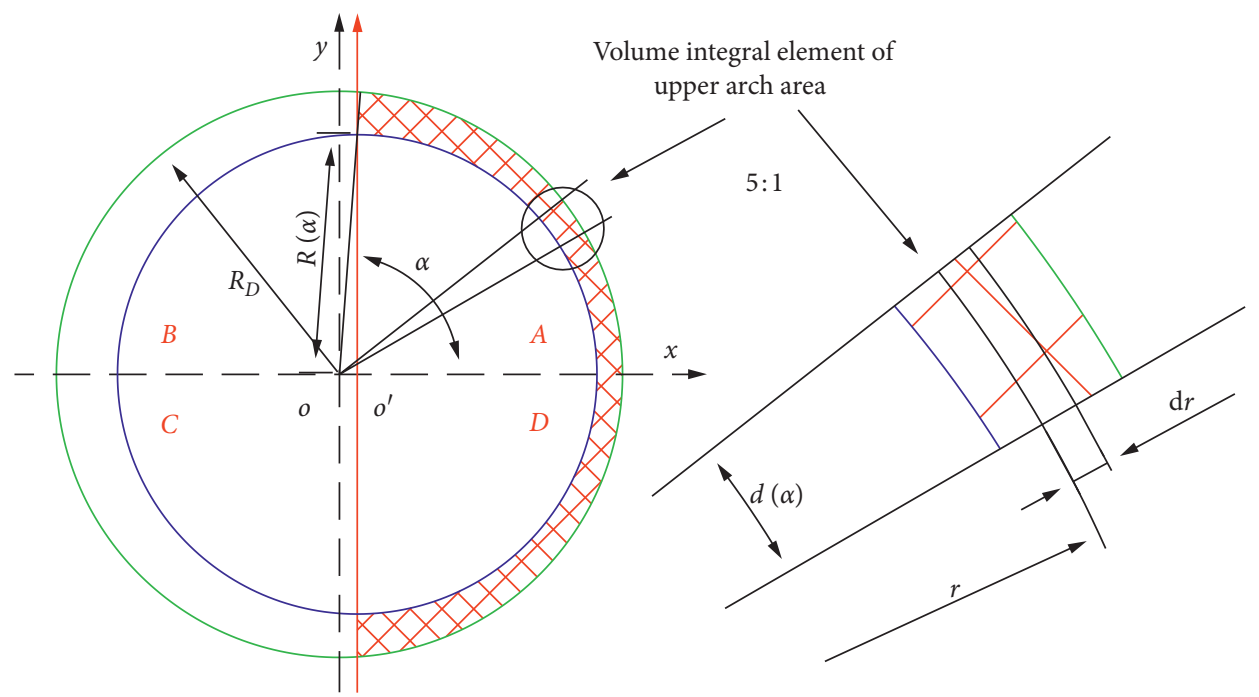

FIgURE 3: Mathematical model of the ore arch area.

Table 1: Particle size coefficient [17].

\begin{tabular}{lcc}
\hline Screening situation & Nominal feeding size $(\mathrm{mm})(B)$ & $K_{t}$ \\
\hline \multirow{3}{*}{ Prescreening } & 0.8 & 1 \\
& 0.6 & 1.05 \\
& 0.3 & 1.1 \\
\hline & 0.8 & 1 \\
No prescreening & 0.65 & 1.1 \\
& 0.55 & 1.2 \\
& 0.45 & 1.3 \\
& 0.35 & 1.4 \\
\hline
\end{tabular}

Chalmers University of Technology in Sweden [20, 21] has obtained the relevant mathematical model by simulating lamination crushing through experiments, as shown in the following equations:

$$
\begin{aligned}
S_{i}= & -4.1387\left(\frac{s}{b}\right)^{2}+4.5386\left(\frac{s}{b}\right)-0.2456 \\
B_{i}\left(x_{N}, \frac{s}{b}\right)= & \left\{1-\left[-0.0095+0.5657\left(\frac{s}{b}\right)\right]\right\} \cdot x_{N}^{18.9539-36.2309(s / b)} \\
& -0.0095 x_{N}+0.5657\left(\frac{s}{b}\right) x_{N}
\end{aligned}
$$$$
x_{N}=\frac{\log _{2}\left(X_{N} / x_{\min }\right)}{\log _{2}\left(x_{0} / x_{\min }\right)},
$$

where $b$ is the compression height of the bulk materials before lamination and crushing, $s$ is the amount of feed compression, $X_{N}$ is the particle size of the Nth layer of the lamination and crushing materials, $x_{\min }$ is the smallest particle size in the product, $x_{\max }$ is the largest particle size in the feed, and $x_{N}$ is the equivalent particle size of the $N$ th layer of laminated crushed materials.

The chamber structure parameters of the cone crusher are the key parameters that affect the performance of the crusher. The bottom angle of the mantle $\alpha$, the length of the parallel zone $l$, the eccentric angle $\gamma$, and the rotating speed $n$ are determined as the design variables of the dual-objective programming model, as shown in the following equation:

$$
X=\left[x_{1}, x_{2}, x_{3}, x_{4}\right]=[n, \gamma, \alpha, l] \text {. }
$$

The value range of the crushing optimization constraints was set by referring to the parameters of the C900 cone crusher. The parameters of C900 are shown in Table 2 where $c$ is open side size, $e$ is eccentricity, and $\beta$ is engagement angle.

(1) According to the calculation of the critical speed and the actual parameters $269-350 \mathrm{r} / \mathrm{min}$, speed $n$ was defined as $250 \leq n \leq 380$.

(2) According to the suspension height of the cone crusher, the eccentric angle was defined as $1^{\circ} \leq \gamma \leq 2^{\circ}$. The swing stroke and eccentricity of the mantle are affected by the eccentric angle.

(3) According to the original parameters and actual design experience, the value range of the bottom angle of the mantle was defined as $40^{\circ} \leq \alpha \leq 60^{\circ}$.

(4) The product quality can be effectively improved by increasing the length of the parallel zone, and the length of the parallel zone $l$ was defined as $130 \leq l \leq 190$.

Therefore, the constraint range of each design variable is as follows:

$$
\left\{\begin{array}{l}
250 \leq n \leq 380 \\
1^{\circ} \leq \gamma \leq 2^{\circ} \\
40^{\circ} \leq \alpha \leq 60^{\circ} \\
130 \leq l \leq 190
\end{array}\right.
$$

The objective function was determined by studying the performance of the cone crusher. The design variables were determined by analyzing the structure parameters and process parameters of the cone crusher. The constraint 
TABLE 2: C900 cone crusher working parameters.

\begin{tabular}{lcccccccc}
\hline$D(\mathrm{~mm})$ & $c(\mathrm{~mm})$ & $Q\left(\mathrm{t} \cdot \mathrm{h}^{-1}\right)$ & $n\left(\mathrm{r} \cdot \mathrm{min}^{-1}\right)$ & $l(\mathrm{~mm})$ & $\alpha\left(^{\circ}\right)$ & $\gamma\left({ }^{\circ}\right)$ & $e(\mathrm{~mm})$ & $\beta\left(\left(^{\circ}\right)\right.$ \\
\hline 1798 & 50 & 990 & 300 & 130 & 45 & 2 & 31.4 & 23 \\
\hline
\end{tabular}

conditions were set by combining the parameters of the cone crusher C900. Comprehensive analysis of the objective optimization problem of the cone crusher was performed using the main objective method, taking productivity as the main objective of crusher optimization and transforming the product quality optimization into nonlinear constraints. According to equations (6), (7), (12), and (13), the dualobjective programming model of cone crusher is established, and the forms are shown in the following equations:

$$
\begin{gathered}
F_{1}(x)=-Q=-\left(Q_{L}-Q_{\text {up }}\right) \longrightarrow \text { min, } \\
X=\left[x_{1}, x_{2}, x_{3}, x_{4}\right]=[n, \gamma, \alpha, l] \\
\left\{\begin{array}{l}
n_{\min } \leq n \leq n_{\max }, \\
l_{\min } \leq l \leq l_{\max }, \\
\alpha_{\min } \leq \alpha \leq \alpha_{\max }, \\
\gamma_{\min } \leq \gamma \leq \gamma_{\max }, \\
P_{\mathrm{CSS}}=\sum_{x \leq \mathrm{CSS}}\left\{\prod_{i=1}^{K_{0}}\left[B_{i} S_{i}+\left(I-S_{i}\right)\right] F_{i}\right\} \leq P_{\mathrm{CSS} \min } .
\end{array}\right.
\end{gathered}
$$

The dual-objective programming model of the cone crusher is solved by using K-T [22] nonlinear sequential quadratic programming method, and the optimization results are shown in Table 3. Figures 4-6 show the effects of changing the bottom angle of the mantle $\alpha$, the length of the parallel zone $l$, and the eccentric angle $\gamma$ on productivity and particle size distribution of crushed products.

As shown in Figures 4(a) and 4(b), crusher productivity is increased from $1008 \mathrm{t} / \mathrm{h}$ to $1238 \mathrm{t} / \mathrm{h}$ at the rate of $23 \%$, as the bottom angle of the mantle $\alpha$ increases from $50^{\circ}$ to $60^{\circ}$. However, the particle size and quality of crushed products decrease, which is less than the closed side setting of broken product percentage from $85 \%$ to $78 \%$. This is due to the decrease of the effective crushing times in the crushing chamber when the bottom angle of the mantle increases.

As shown in Figures 5(a) and 5(b), crusher productivity is decreased from $998 \mathrm{t} / \mathrm{h}$ to $850 \mathrm{t} / \mathrm{h}$ at the rate of $15 \%$,, as the length of the parallel zone $l$ increases from $140 \mathrm{~mm}$ to $190 \mathrm{~mm}$. However, the particle size and quality of crushed products increase, which is less than the closed side setting of broken product percentage which increases by about $9.6 \%$. This is because as the parallel zone increases, ores were more fully broken, but the broken time results in a decline in productivity growth.

As shown in Figures 6(a) and 6(b), crusher productivity and the particle size and quality are increased, as the eccentric angle $\gamma$ increases from $1.4^{\circ}$ to $2^{\circ}$. This is because the eccentricity of the crusher and swing stroke of the mantle increase with the increase of eccentric angle.

The above research shows that the influence of the structure parameters of the crusher on the productivity and product quality is mutually restricted, and there is a strong coupling relationship. Therefore, both productivity optimization and product quality optimization are taken into account, the optimal performance parameters of the crusher C900 were obtained, the mantle bottom angle is in the range of $50^{\circ}$ to $60^{\circ}$, the length of the parallel zone is in the range of $140 \mathrm{~mm}-190 \mathrm{~mm}$, and the eccentric angle is in the range of $1.4^{\circ}-2^{\circ}$. The optimal structural parameters of the C900 crusher chamber was obtained: the swing speed of the mantle, the length of the parallel zone, the bottom angle of the mantle, the eccentric angle, the eccentricity, and the engagement angle are $285 \mathrm{r} / \mathrm{min}, 150 \mathrm{~mm}, 55^{\circ}, 2^{\circ}, 44.8 \mathrm{~mm}$, and $23^{\circ}$, respectively.

\section{DEM Simulation of Crushing Process}

The DEM provides a bonding and energy accumulation crushing model, which can accurately describe the crushing process of ores under the action of equipment. Hasankhoei et al. [23] and Cleary et al. [24] have proved to be a powerful tool for studying the flow of bulk materials and ore crushing behavior. In this paper, based on the coarse broken iron ores in the rotary crusher, the ore particle model was established by using DEM software. The dynamic characteristics of the model were simulated by combining with the three-dimensional cone crusher model in order to study the influence of relevant parameters on the performance of the crusher.

5.1. Physical Properties of Ore after Coarse Crushing. Before the ore modeling with DEM software, the basic physical and mechanical properties of iron ore were explored through rock uniaxial compression $[25,26]$, fracture toughness, rock material damage, and other experiments. The grain size, structure size, internal porosity, pore radius, coordination number, and other factors of the ore were analyzed by computed tomography (CT) nondestructive testing technology. The DEM virtual ore model can more truly reflect the physical characteristics and crushing characteristics from the experimental results. Figure 7 shows the cutting and sampling from the crude ore after the rotary crusher. The equipment used is a cutting machine and a drilling prototype to make the iron ore into regular cylindrical specimens for the mechanical properties experiment.

For the collected specimens, the internal structure and characteristics of the ore were observed through nondestructive testing with CT. The internal structure of the ore is visually characterized through three-dimensional technology $[27,28]$. Finally, the relationship between structure and performance was established based on the experimental data. Figures 8(a) and 8(b) show the technical scheme of CT nondestructive testing and CT. 
TABLE 3: Optimization calculation results.

\begin{tabular}{|c|c|c|c|c|c|c|c|c|c|}
\hline \multicolumn{2}{|l|}{ Design variable } & $Q\left(\mathrm{t} \cdot \mathrm{h}^{-1}\right)$ & $P_{c s s}(\%)$ & $n\left(\mathrm{r} \cdot \mathrm{min}^{-1}\right)$ & $l(\mathrm{~mm})$ & $\alpha\left({ }^{\circ}\right)$ & $\gamma\left({ }^{\circ}\right)$ & $e(\mathrm{~mm})$ & $\beta\left({ }^{\circ}\right)$ \\
\hline \multicolumn{2}{|c|}{ Before optimization } & 990 & 80.0 & 300 & 130 & 45 & 2 & 31.4 & 23 \\
\hline & 1 & 1008 & 85.0 & 293 & 150 & 50 & 2 & 37.4 & 23 \\
\hline \multirow[t]{3}{*}{ Bottom angle } & 2 & 1126 & 81.2 & 275 & 150 & 55 & 2 & 44.8 & 23 \\
\hline & 3 & 1238 & 78.0 & 260 & 150 & 60 & 2 & 54.3 & 23 \\
\hline & 1 & 998 & 82.0 & 300 & 140 & 50 & 2 & 37.4 & 23 \\
\hline \multirow[t]{3}{*}{ Parallel zone } & 2 & 896 & 87.2 & 300 & 170 & 50 & 2 & 37.4 & 23 \\
\hline & 3 & 850 & 89.6 & 300 & 190 & 50 & 2 & 37.4 & 23 \\
\hline & 1 & 710 & 77.3 & 320 & 150 & 50 & 1.4 & 30.8 & 23 \\
\hline \multirow[t]{2}{*}{ Eccentric angle } & 2 & 890 & 80.3 & 320 & 150 & 50 & 1.6 & 32.2 & 23 \\
\hline & 3 & 986 & 81.6 & 320 & 150 & 50 & 1.8 & 34.5 & 23 \\
\hline \multicolumn{2}{|c|}{ After optimization } & 1151 & 83.2 & 285 & 150 & 55 & 2 & 44.8 & 23 \\
\hline
\end{tabular}

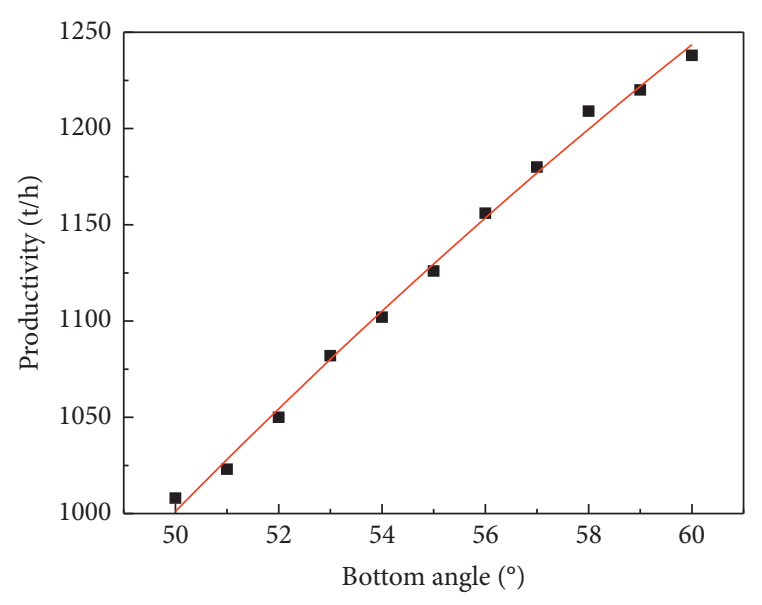

(a)

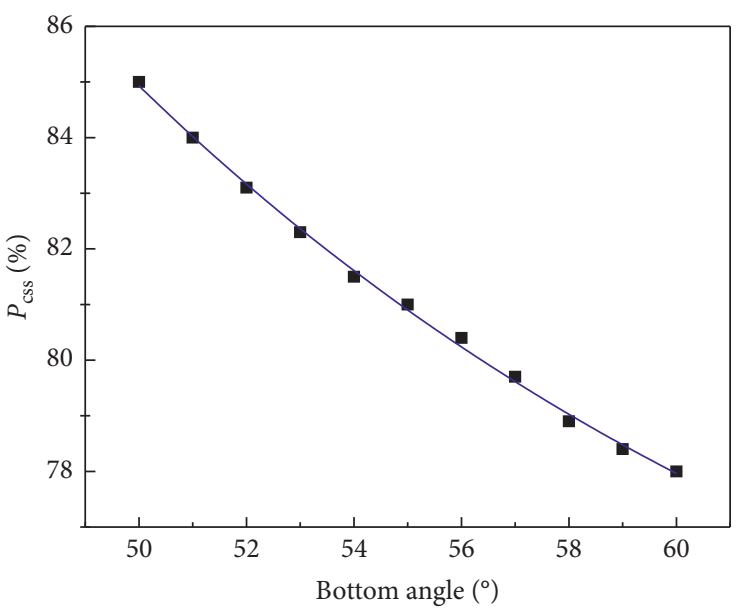

(b)

FIgURE 4: The effect of the bottom angle of the mantle on the (a) productivity and (b) product quality.

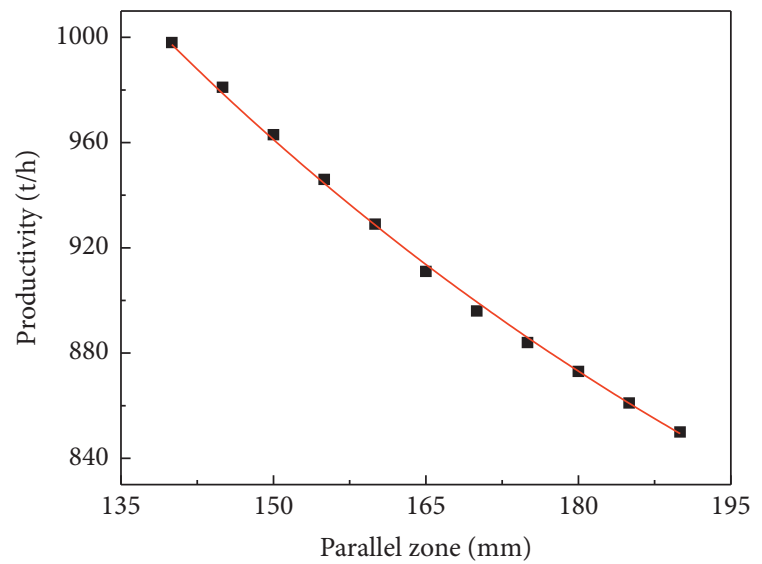

(a)

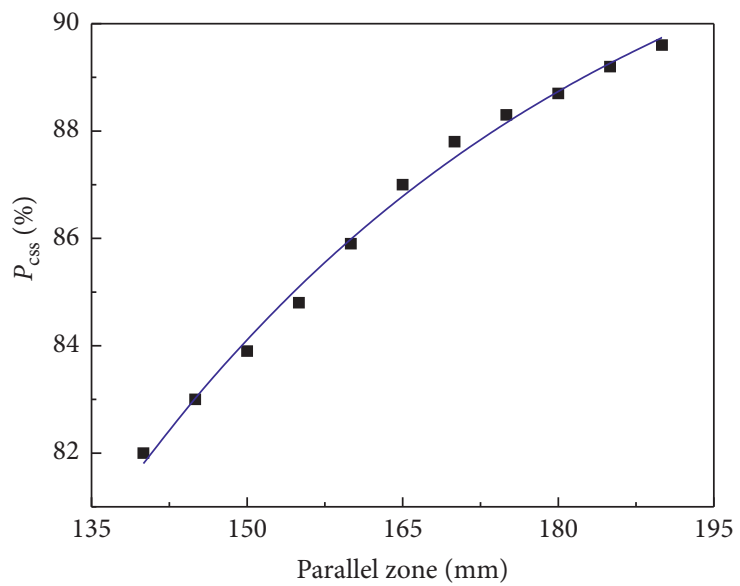

(b)

Figure 5: The effect of parallel zone length on (a) productivity and (b) product quality.

The test conditions were voltage $100 \mathrm{kV}$, current $50 \mu \mathrm{A}$, and resolution $1.12 \mu \mathrm{m}$. A full-diameter CT scan test was performed on ore samples, and the internal three-dimensional (3D) structure data volume of the sample was obtained for threedimensional display. After that, different internal substances were extracted by using the gray difference for three-dimensional rendering. The internal structure of the ore was observed to understand the structural characteristics of the internal pores and fractures of the ore. Figures 9(a) and 9(b) show the threedimensional display and rendering of iron ore. The red area 


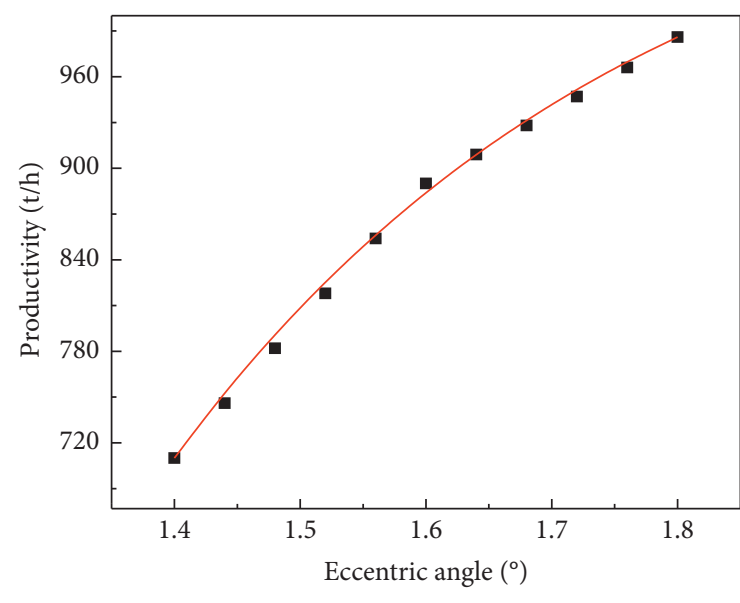

(a)

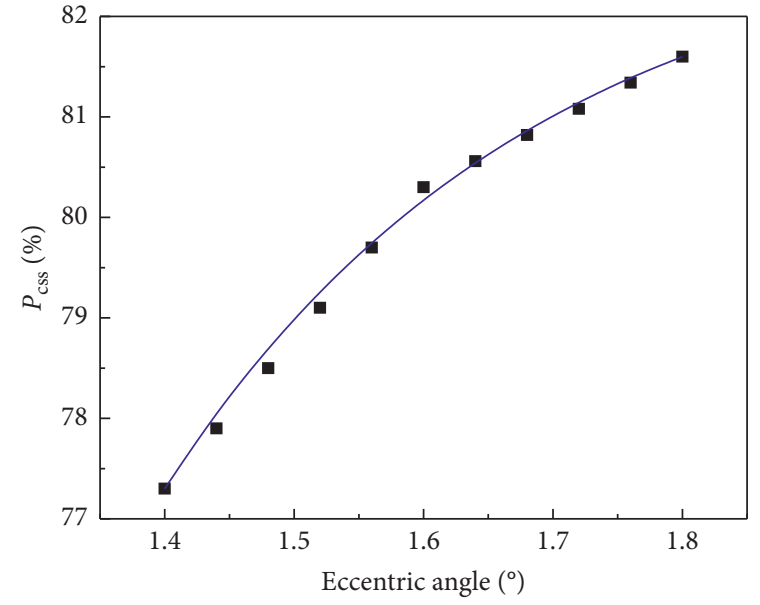

(b)

Figure 6: The effect of eccentric angle on (a) productivity and (b) product quality.

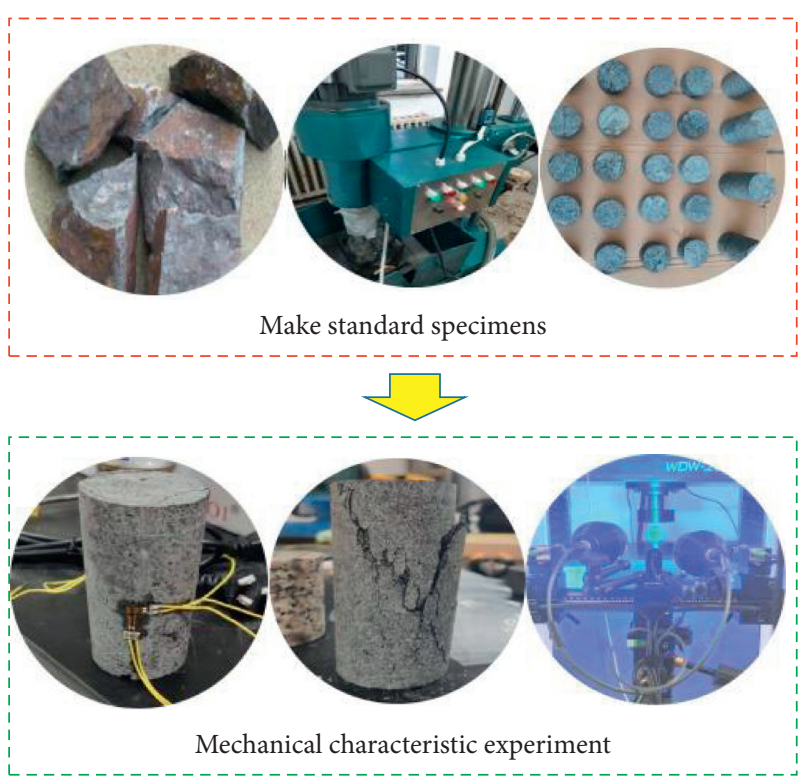

FIgURE 7: Standard specimens and mechanical properties experiment.

shows the cracks. The cracks were extracted by threshold segmentation. The volume percentage of the study area (i.e., porosity) occupied by the cracks is $10.18 \%$.

Figures 10(a) and 10(b) show the three-dimensional rendering of iron ore porosity. The extracted pores were marked with different colors for each isolated pore. At the same time, the pores were marked and sieved. The pore equivalent diameter (EqD) sieve is shown in Figures 11(a)11(h). The number of equivalent diameters of different pores and the percentage of the total pore volume are shown in Table 4.

The characteristic parameters such as porosity, coordination number, pore radius, and pore volume were obtained through the experimental exploration of the ore after coarse crushed by the gyratory crusher. The number of pore equivalent diameters in the range of
$9<\mathrm{EqD} \leq 15 \mu \mathrm{m}$ is the largest, which is 11484 . The pore volume with pore equivalent diameter in the range of $\mathrm{EqD}>60 \mu \mathrm{m}$ accounts for a relatively large amount, accounting for $88.01 \%$. The maximum pore radius, the average pore radius, the maximum pore volume, the average pore volume, the maximum coordination number, the average coordination number, and the compressive strength are $11.414 \mu \mathrm{m}, 1.678 \mu \mathrm{m}, 121519 \mu \mathrm{m}^{3}$, $335.833 \mu \mathrm{m}^{3}, 109,3$, and $148 \mathrm{MPa}$, respectively (see Table 4).

5.2. Ore Particle Model. In order to characterize the ore particle model well, bonded particle model (BPM) was selected. The BPM model was published by Potyondy et al. [29] and A. R. Hasankhoei for the purpose of simulating ore breakage. The approach has been applied and further developed by Cho et al. and Johansson et al. [30, 31]. The concept is based on bonding or gluing a packed distribution of spheres together forming a breakable body.

When setting the crushed ore particles, firstly, a certain amount of particles were combined to form ore particles through the bonding bond at a given time. When subjected to crushing force, the particles formed by the bonding bond will be dispersed to show the broken state. At this time, the bonding bond is broken. The larger the number of broken bonds, the better the crushing effect and the higher the product quality. This paper mainly analyzes the impact of different parameters on the crushing effect. Because of the large amount of crushed iron ore, the influence of the shape of the ore was not considered, and the iron ore model was equivalent to a spherical shape. Figure 12 shows a schematic diagram of ore model generation and crushing.

Since the particle size of the ore feed cannot be less than $100 \mathrm{~mm}$, the design iron ore model diameter is $100 \mathrm{~mm}$. According to the physical properties of the iron ore obtained by experiments, such as the porosity and coordination number, the diameter of the fraction used to fill the iron ore particles was determined to be $5 \mathrm{~mm}$. The empirical equation (17) for 


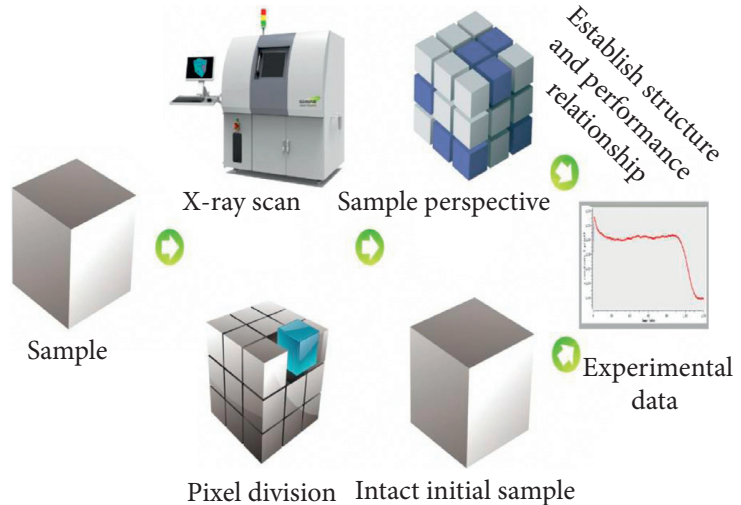

(a)

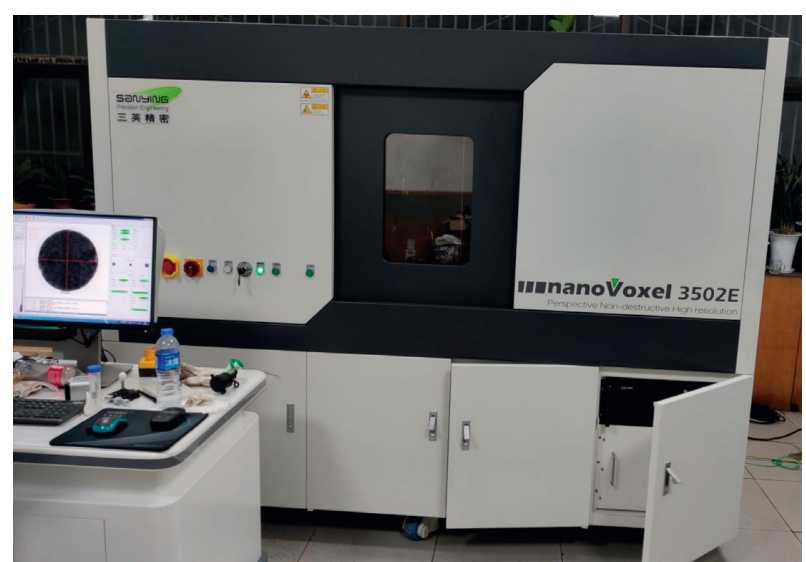

(b)

FIgUre 8: (a) Technical scheme of CT nondestructive testing; (b) CT.

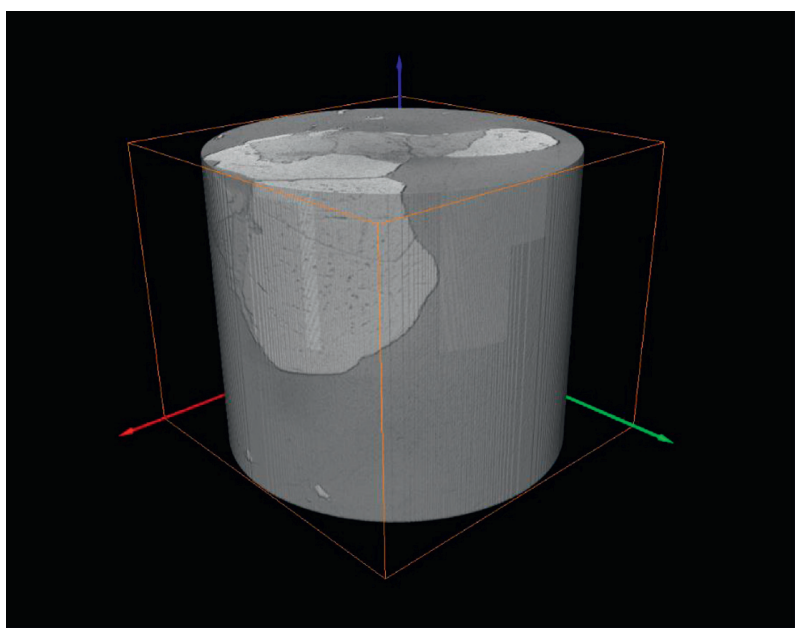

(a)

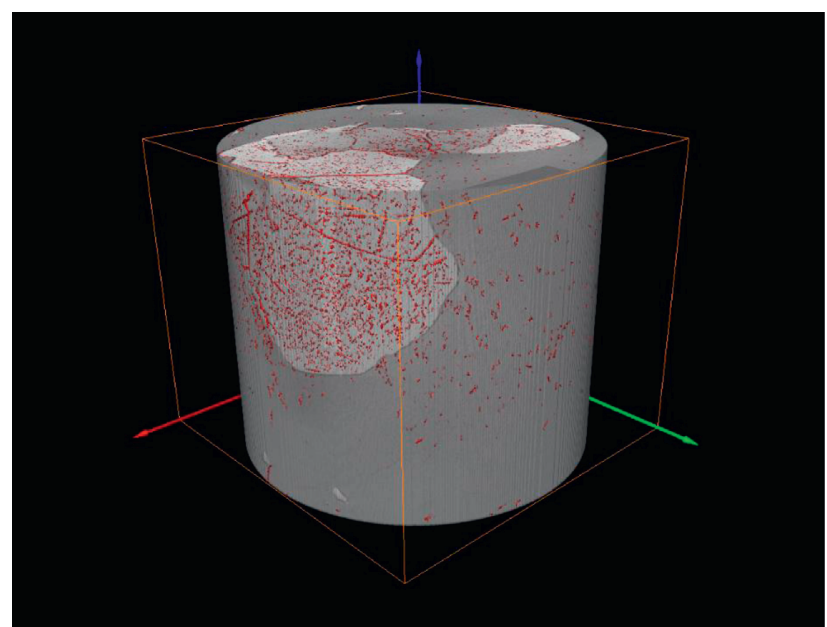

(b)

Figure 9: (a) 3D structure display and (b) 3D rendering of the ore.

determining the number of filling particles given in the DEM was used to calculate the number of filling fractions:

$$
\alpha * V_{\text {real }}=N * V_{\text {Fraction }},
$$

where $\alpha$ is particle filling coefficient, $V_{\text {real }}$ is the volume of feed particle, $N$ is the number of filled fractions, and $V_{\text {Fraction }}$ is the volume of filled fractions.

The recommended coefficient of filling coefficient is 0.56 , and the fraction for filling should be around the origin of the coordinate, and the large fraction should completely include $V_{\text {real }}$.

5.3. Simulation Analysis. Firstly, import the crusher chamber model drawn by SolidWorks into the geometry module, and set the motion characteristics for each part. The movement of the mantle includes two: one is its own rotation movement, the speed is very low, generally $10 \sim 15 \mathrm{r} / \mathrm{min}$, and the other is the eccentric movement around the axis of the concave. The eccentric movement speed is specifically set according to the optimization result, and the movement time is set to $5 \mathrm{~s}$.

Secondly, set the basic property parameters of iron ore and liner materials in the globals module, including density, Poisson's ratio, and shear modulus. Define the properties of fraction particles and whole particles in the particle panel, including particle radius, volume, and mass. The fraction particle radius is $5 \mathrm{~mm}$. Because of the soft ball contact model, the actual contact radius is slightly larger than $5 \mathrm{~mm}$, which is defined as $5.5 \mathrm{~mm}$ here, and the whole particle is $50 \mathrm{~mm}$.

During the operation of the crusher, the ore and the ore, and the ore and the liner are squeezed into each other. Therefore, it is necessary to separately set the coefficient of restitution between the ore and the ore, the coefficient of static friction, the coefficient of dynamic friction, and the three coefficients between the ore and the liner.

Finally, determine the simulation time step and divide the mesh. Generally, 2-3 times the radius of the smallest particle 


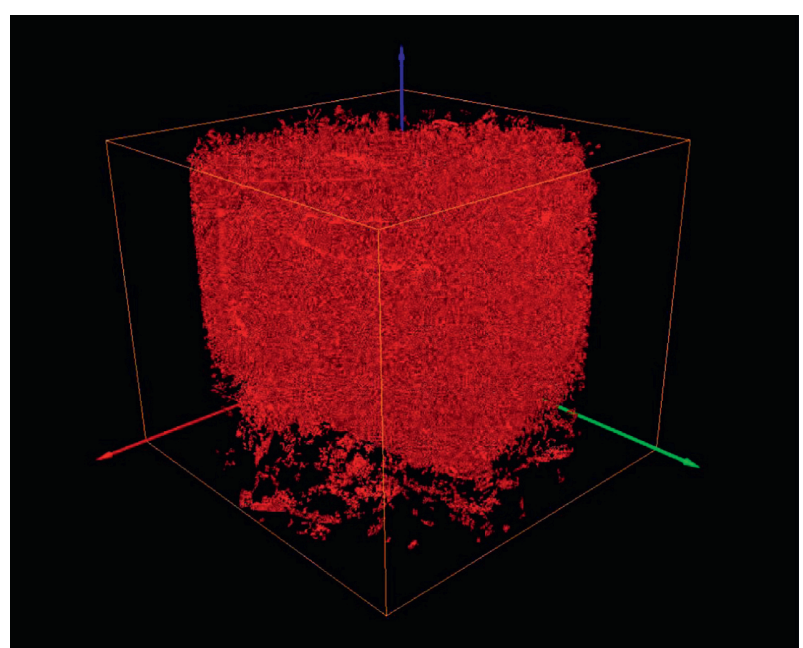

(a)

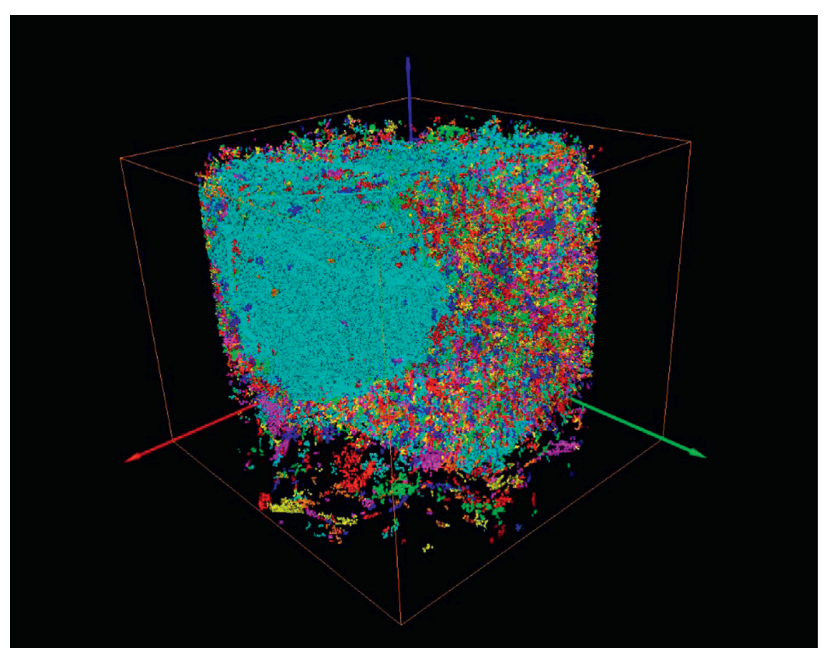

(b)

Figure 10: (a) 3D structure display and (b) 3D rendering of the ore porosity.

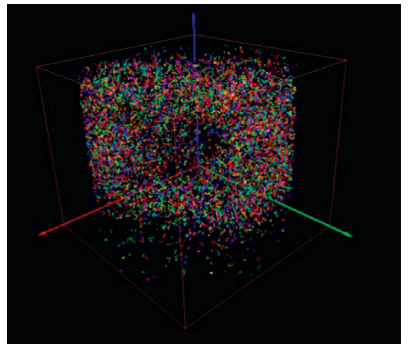

(a)

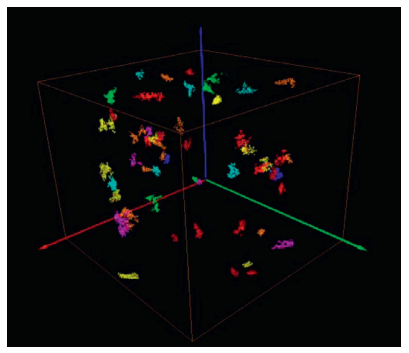

(e)

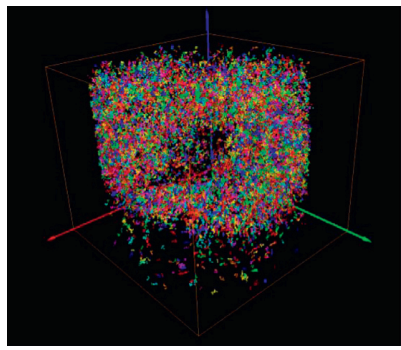

(b)

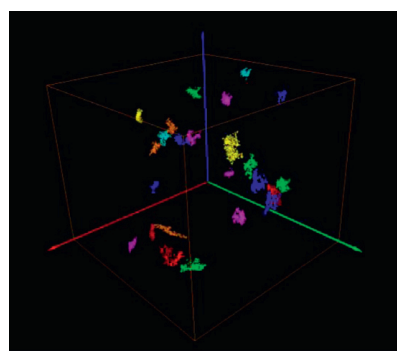

(f)

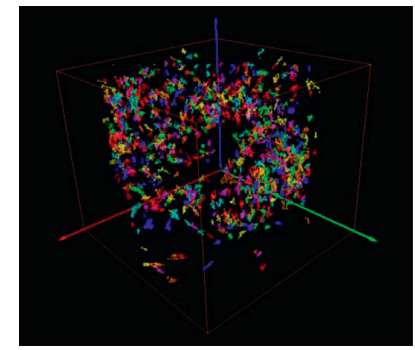

(c)

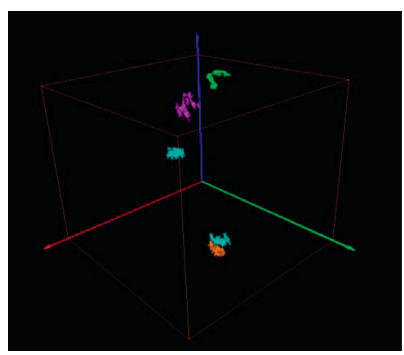

(g)

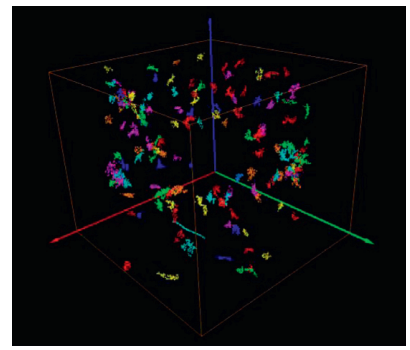

(d)

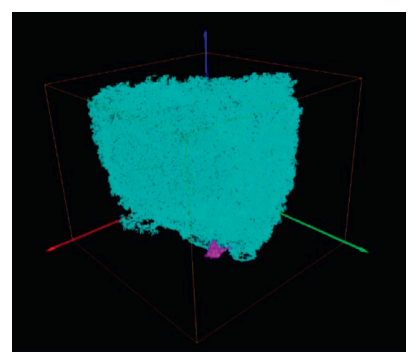

(h)

Figure 11: (a-h) Screening diagram of different pore equivalent diameters (unit: $\mu \mathrm{m}$ ). (a) EqD $\leq 9$. (b) $9<\mathrm{EqD} \leq 15$. (c) $15<$ EqD $\leq 20$. (d) $20<\mathrm{EqD} \leq 25$. (e) $25<\mathrm{EqD} \leq 30$. (f) $30<\mathrm{EqD} \leq 40$. (g) $40<\mathrm{EqD} \leq 60$. (h) $\mathrm{EqD}>60$.

element is selected as the basis for meshing. In this simulation, 2 times the radius of the smallest particle element $5 \mathrm{~mm}$ is selected as the ideal side length of the mesh element.

The time step is determined by the Rayleigh [13] wave method. For a system composed of different particles, the time step was calculated as follows:

$$
\Delta t=\left[\frac{\pi R}{0.163 v+0.877} \sqrt{\frac{\rho}{G}}\right]_{\min },
$$

where $v$ is particle velocity, $\rho$ is particle density, $G$ is shear modulus, and $R$ is particle radius.
Simulation was carried out according to the parameters in Table 3, and the total number of ore bonding bonds $N$ was set as 144,298. Figures 13(a)-13(d) show the DEM simulation of the crushing process of the cone crusher at different moments and the velocity cloud diagram of the particles in the crushing chamber.

5.4. Influence of Key Parameters on Crushing Effect. In Table $5, N$ is the total number of ore bonding bonds and $M$ is the number of ore fracture bonds. The bottom angle of the mantle $\alpha$, the length of the parallel zone $l$, and the eccentric angle $\gamma$ are changed respectively for simulation. For different 
TABLE 4: Number of different pores and percentage of the total pore volume.

\begin{tabular}{lcc}
\hline $\mathrm{EqD}(\mu \mathrm{m})$ & Number & Percentage of total pore volume (\%) \\
\hline $\mathrm{EqD} \leq 9$ & 8425 & 2.16 \\
$9<\mathrm{EqD} \leq 15$ & 11484 & 6.33 \\
$15 \leq \mathrm{EqD} \leq 20$ & 813 & 1.68 \\
$20 \leq \mathrm{EqD} \leq 25$ & 153 & 0.69 \\
$25 \leq \mathrm{EqD} \leq 30$ & 60 & 0.52 \\
$30 \leq \mathrm{EqD} \leq 40$ & 25 & 0.41 \\
$40 \leq \mathrm{EqD} \leq 60$ & 5 & 0.20 \\
$\mathrm{EqD}>60$ & 2 & 88.01 \\
\hline
\end{tabular}

The above data provide a certain parameter setting reference for establishing the ore model in the DEM in the next step and can make the broken ore model established in the DEM closer to the real situation.

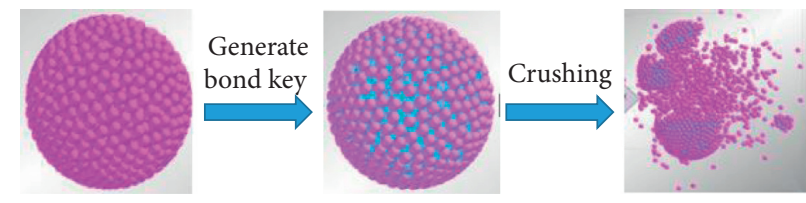

FIGURE 12: Schematic diagram of ore model generation and crushing.

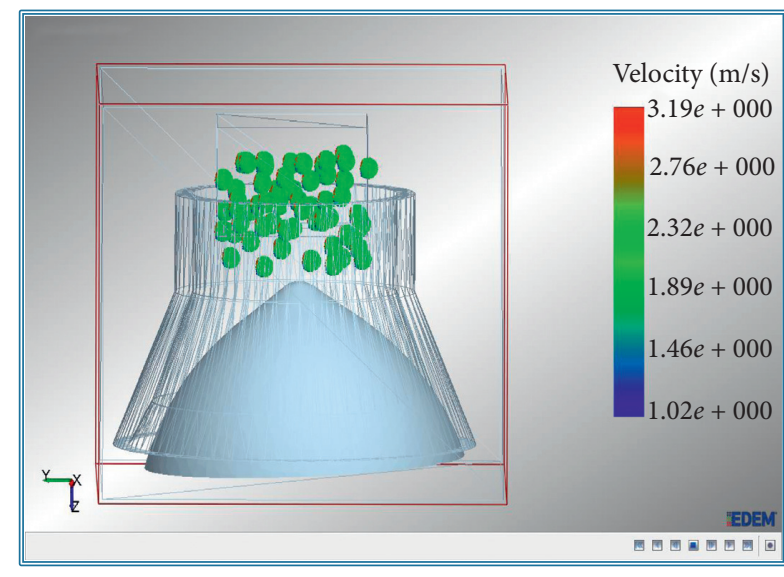

(a)

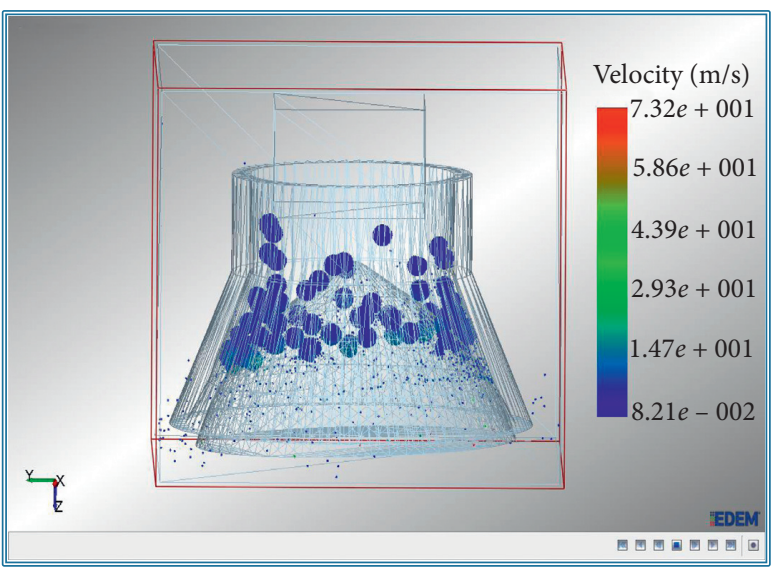

(c)

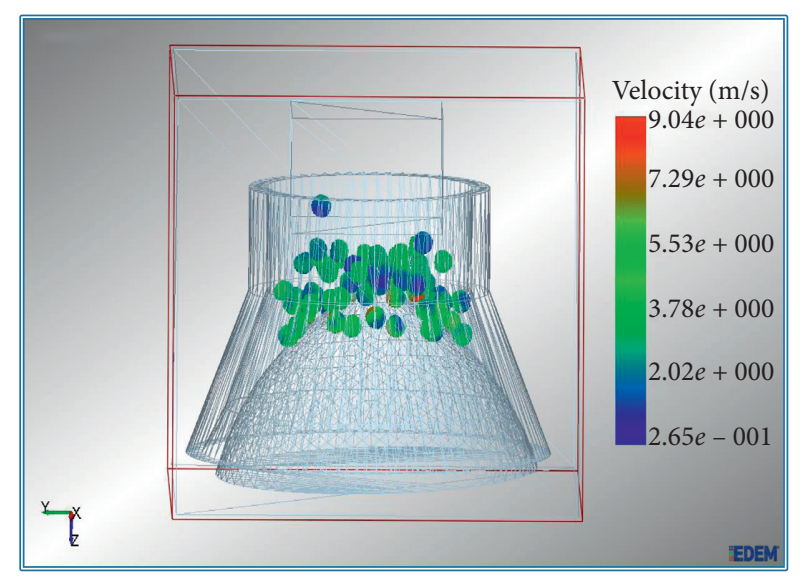

(b)

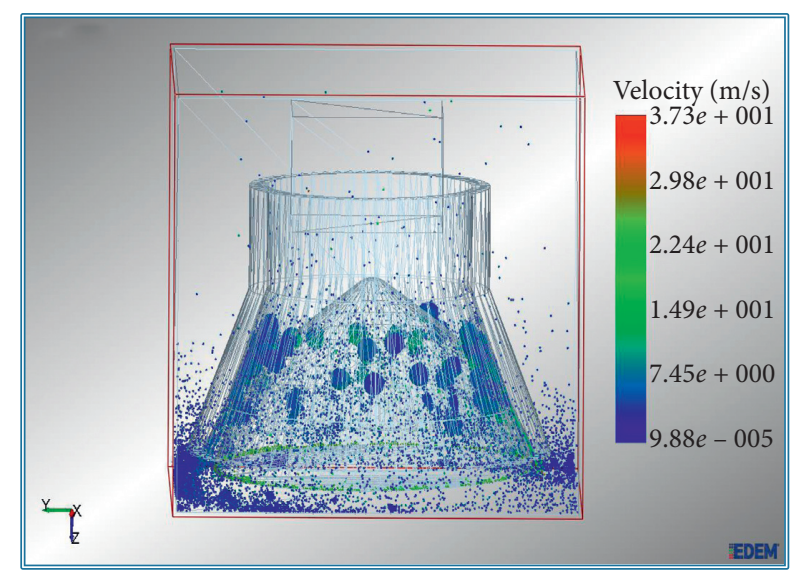

(d)

Figure 13: Crushing process of cone crusher at different times. (a) Time: $0.10 \mathrm{~s}$; (b) time: $0.26 \mathrm{~s}$; (c) time: $0.74 \mathrm{~s}$; (d) time: $1.44 \mathrm{~s}$.

variable values, the corresponding number of ore fracture bonds and $P_{c s s}$ are shown in Table 5 . The breaking rule of ore bonding bond with crushing time is shown in Figures 14(a)14(c).
It can be seen from the above that when the bottom angle of the mantle increases from $50^{\circ}$ to $60^{\circ}$, the number of bond breaks decreases from 130,589 to 118,901 , and the broken percentage decreases from $90.5 \%$ to $82.4 \%$. And when the 
TABLE 5: Comparison of simulation and numerical analysis results.

\begin{tabular}{lcccccccc}
\hline Key structural parameters & Serial number & $\alpha\left(^{\circ}\right)$ & $l(\mathrm{~mm})$ & $\gamma\left({ }^{\circ}\right)$ & $N$ & $M$ & Simulation Pcss $(\%)$ & Numeral calculationsPcss $(\%)$ \\
\hline \multirow{3}{*}{ Bottom angle } & 1 & 50 & 150 & 2 & 144298 & 130589 & 90.5 & 85.0 \\
& 2 & 55 & 150 & 2 & 144298 & 127926 & 88.6 & 81.2 \\
Parallel zone & 3 & 60 & 150 & 2 & 144298 & 118901 & 82.4 & 78.0 \\
& 1 & 55 & 140 & 2 & 144298 & 126838 & 87.9 & 82.0 \\
\hline \multirow{3}{*}{ Eccentric angle } & 2 & 55 & 170 & 2 & 144298 & 131599 & 91.2 & 87.2 \\
& 3 & 55 & 190 & 2 & 144298 & 136650 & 94.7 & 77.3 \\
\hline
\end{tabular}

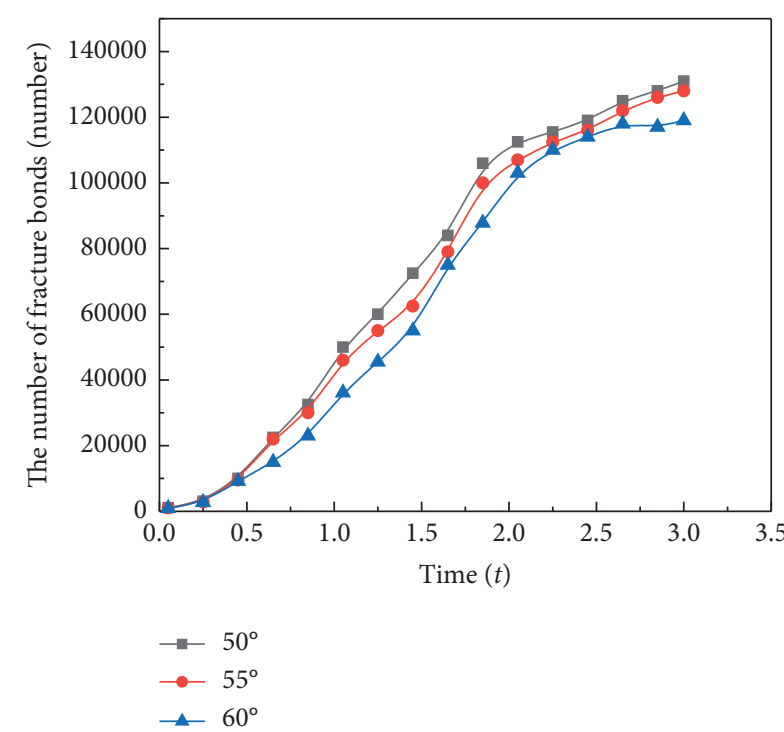

(a)

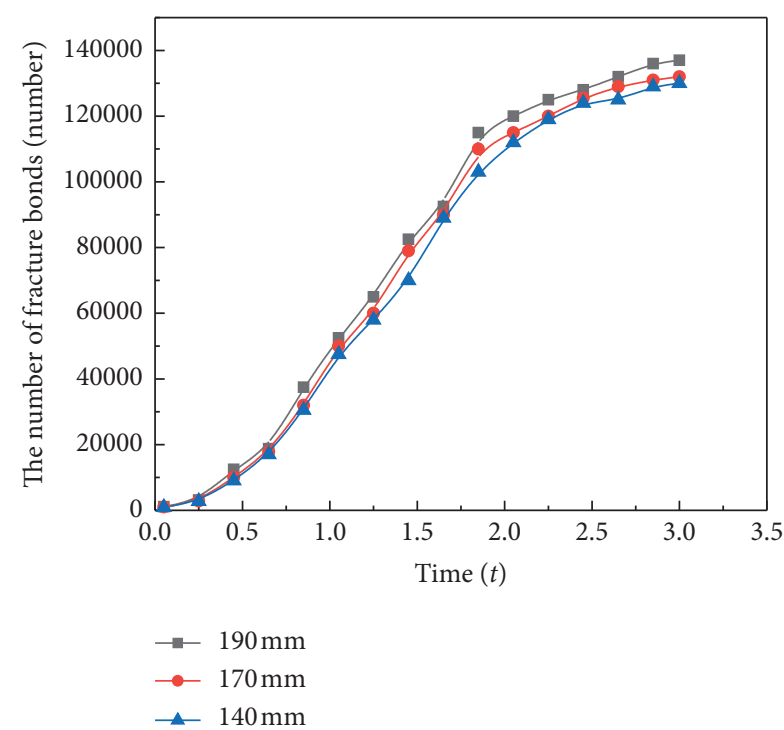

(b)

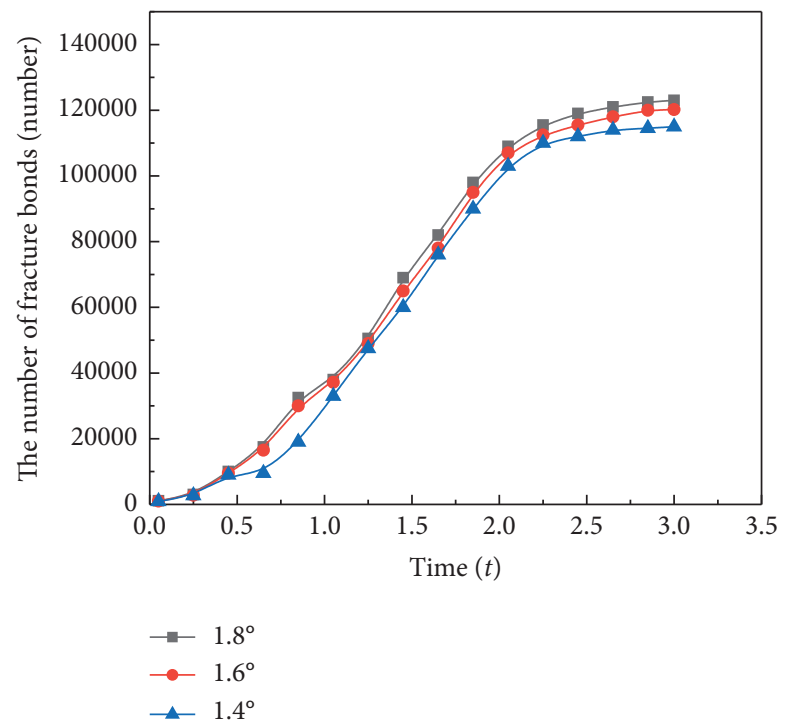

(c)

Figure 14: The influence of different parameters of cone crusher on the crushing effect. (a) Bottom angle; (b) parallel zone; (c) eccentric angle.

length of the parallel zone increases from $140 \mathrm{~mm}$ to $190 \mathrm{~mm}$, the number of bond breakages increases from 126838 to 136650 and the broken percentage increases from
$87.9 \%$ to $94.7 \%$. While when the eccentric angle increased from $1.4^{\circ}$ to $2^{\circ}$, the number of bond breaks increased from 115,149 to 122,941 , and the broken percentage increased 
from $79.8 \%$ to $85.2 \%$. The simulation value is slightly higher than the numerical calculation value, but the trend of the broken percentage with the change of the bottom angle of the mantle, the length of the parallel zone, and the eccentric angle is consistent.

\section{Conclusion}

By analyzing the movement state of the ore in the crushing chamber, the cone crusher productivity and product quality are used as the objective functions to study the influence of the chamber structure parameters on the crusher performance with the method of optimized numerical calculation. The main conclusions of this paper are as follows:

(1) In order to obtain a more accurate productivity model, it is necessary to remove the blockage ore uplift in the traditional model. For this reason, considering the influence of the ore arching of the blockage layer in the $A$ and $D$ areas, the traditional productivity model was revised to improve the calculation accuracy of the crusher's productivity. For the C900 cone crusher, the relative error of the revised productivity model calculation value is reduced by $16 \%$.

(2) Taking the parameters such as mantle bottom angle, parallel zone length, and the eccentric angle of the chamber structure as optimization variables, a dualobjective programming model about the productivity and product quality for the cone crusher was established. The optimal parameter matching scheme of C900 cone crusher performance was obtained: The swing speed of the mantle, the length of the parallel zone, the bottom angle of the mantle, the eccentric angle, the eccentricity, and the engagement angle are $285 \mathrm{r} / \mathrm{min}, 150 \mathrm{~mm}, 55^{\circ}, 2^{\circ}$, $44.8 \mathrm{~mm}$, and $23^{\circ}$, respectively. After optimization, the productivity and the percentage of crushed products of the C900 cone crusher can be increased by about $2 \%$ and $2.1 \%$, respectively.

(3) Based on the physical characteristics of the iron ore after coarse crushing by the gyratory crusher, the discrete element method is used to simulate the crushing process. The simulation results are consistent with the trend of the numerical calculation results, verifying the feasibility and reliability of the dual-objective programming model of the cone crusher as well as the optimization numerical method.

\section{Data Availability}

The data used to support the findings of this study are available from the corresponding author upon request.

\section{Conflicts of Interest}

The authors declare that they have no conflicts of interest regarding the publication of this paper.

\section{Acknowledgments}

The authors extend special thanks for the support of mining machinery technicians of Northern Heavy Industry (NHI) for the research work.

\section{References}

[1] M. Bengtsson, "Modelling energy and size distribution in cone crushers," Minerals Engineering, vol. 139, Article ID 105869, 2019.

[2] A. Gröndahl, G. Asbjörnsson, E. Hulthén, and M. Evertsson, "Diagnostics of cone crusher feed segregation using power draw measurements," Minerals Engineering, vol. 127, no. 10, pp. 15-21, 2018.

[3] E. Lee and C. M. Evertsson, "A comparative study between cone crushers and theoretically optimal crushing sequences," Erals Engineering, vol. 24, no. 3-4, pp. 188-194, 2011.

[4] E. Lee and C. M. Evertsson, "Optimizing and evaluating theoretical concepts of compressive crushing," 26th International Mineral Processing Congress, vol. 21, no. 2, pp. 1052-1071, 2012.

[5] Z. Wang, W. Du, J. Wang et al., "Research and application of improved adaptive MOMEDA fault diagnosis method," Measurement, vol. 140, pp. 63-75, 2019.

[6] Z. Zhang, T. Ren, J. Cheng, and X. Jin, "The improved model of inter-particle breakage considering the transformation of particle shape for cone crusher," Minerals Engineering, vol. 112, pp. 11-18, 2017.

[7] D. Huang, X. Fan, D. Wu, and F. Yao, "Multi-objective planning of cone crusher chamber, output and size reduction," Minerals Engineering, vol. 20, no. 2, pp. 163-172, 2007.

[8] K. T. Atta, T. Euzébio, H. Ibarra, V. S. Moreira, and A. Johansson, "Extension, validation, and simulation of a cone crusher model," IFAC-PapersOnLine, vol. 52, no. 14, pp. 1-6, 2019.

[9] M. Bengtsson, E. Hulthén, and C. M. Evertsson, "Size and shape simulation in a tertiary crushing stage, a multi objective perspective," Minerals Engineering, vol. 77, no. 5, pp. 72-77, 2015.

[10] D. M. Franks, D. V. Boger, C. M. Côte, and D. R. Mulligan, "Sustainable development principles for the disposal of mining and mineral processing wastes," Resources Policy, vol. 36, no. 2, pp. 114-122, 2011.

[11] P. W. Cleary, M. D. Sinnott, R. D. Morrison, S. Cummins, and G. W. Delaney, "Analysis of cone crusher performance with changes in material properties and operating conditions using DEM," Minerals Engineering, vol. 100, no. 10, pp. 49-70, 2017.

[12] G. W. Delaney, R. D. Morrison, M. D. Sinnott, S. Cummins, and P. W. Cleary, "DEM modelling of non-spherical particle breakage and flow in an industrial scale cone crusher," Minerals Engineering, vol. 74, no. 4, pp. 112-122, 2015.

[13] J. Quist and C. M. Evertsson, "Cone crusher modelling and simulation using DEM," Minerals Engineering, vol. 85, pp. 92-105, 2016.

[14] Z. Chen, G. Wang, D. Xue, and Q. Bi, "Simulation and optimization of gyratory crusher performance based on the discrete element method," Powder Technology, vol. 376, pp. 93-103, 2020.

[15] S. Nikolov, "A performance model for impact crushers," Minerals Engineering, vol. 15, no. 10, pp. 715-721, 2002.

[16] E. Hulthén and C. Magnus Evertsson, "Real-time algorithm for cone crusher control with two variables," Minerals Engineering, vol. 24, no. 9, pp. 987-994, 2011. 
[17] Y. Jiang, Optimization Design of Cone Crusher Chamber Shape, Wuhan University of Science and Technology, Wuhan, China, 2015.

[18] S. R. Broadbent and T. G. Callcott, "Coal breakage processes. A new analysis of coal breakage processes," Journal of the Institute of Fuel, vol. 29, pp. 524-539, 1956.

[19] A. J. Lynch, Mineral Crushing and Grinding Circuits, Elsevier Scientific Publishing Company, New York, NY, USA, 1977.

[20] C. M. Evertsson, "Output prediction of cone crushers," Minerals Engineering, vol. 11, no. 3, pp. 215-231, 1997.

[21] M. Evertsson, Cone Crusher Performance, Chalmers University of Technology, Gothenburg, Sweden, 2015.

[22] Z. Li, S. Liu, W. Ren, J. Fang, Q. Zhu, and Z. Dun, "Multiscale laboratory study and numerical analysis of water-weakening effect on shale," Advances in Materials Science and Engineering, vol. 2020, Article ID 5263431, 14 pages, 2020.

[23] A. R. Hasankhoei, M. Maleki-Moghaddam, A. Haji-Zadeh, M. E. Barzgar, and S. Banisi, "On dry SAG mills end liners: physical modeling, DEM-based characterization and industrial outcomes of a new design," Minerals Engineering, vol. 141, Article ID 105835, 2019.

[24] P. W. Cleary, R. D. Morrison, and G. W. Delaney, "Incremental damage and particle size reduction in a pilot SAG mill: DEM breakage method extension and validation," Minerals Engineering, vol. 128, pp. 56-68, 2018.

[25] Y. Wang, B. Zhang, S. H. Gao, and C. H. Li, "Investigation on the effect of freeze-thaw on fracture mode classification in marble subjected to multi-level cyclic loads," Theoretical and Applied Fracture Mechanics, vol. 111, no. 2, p. 102847, 2021.

[26] D. Yin, S. Chen, Y. Ge, and R. Liu, "Mechanical properties of rock-coal bi-material samples with different lithologies under uniaxial loading," Journal of Materials Research and Technology, vol. 10, no. 2, pp. 322-338, 2021.

[27] Q. Meng, H. Wang, W. Xu, X. Zhuang, and T. Rabczuk, "Three-dimensional mesoscale computational modeling of soil-rock mixtures with concave particles," Engineering Geology, vol. 277, no. 11, Article ID 105802, 2020.

[28] Q.-X. Meng, W.-Y. Xu, H.-L. Wang, X.-Y. Zhuang, W.-C. Xie, et al.,and T Rabczuk, "DigiSim-an open source software package for heterogeneous material modeling based on digital image processing," Advances in Engineering Software, vol. 148, no. 10, Article ID 102836, 2020.

[29] D. O. Potyondy and P. A. Cundall, "A bonded-particle model for rock," International Journal of Rock Mechanics and Mining Sciences, vol. 41, no. 22, pp. 1329-1364, 2004.

[30] N. Cho, C. D. Martin, and D. C. Sego, "A clumped particle model for rock," International Journal of Rock Mechanics and Mining Sciences, vol. 44, no. 7, pp. 997-1010, 2007.

[31] M. Johansson, J. Quist, M. Evertsson, and E. Hulthén, "Cone crusher performance evaluation using DEM simulations and laboratory experiments for model validation," Minerals Engineering, vol. 103-104, pp. 93-101, 2017. 